\title{
Pharmacists' Willingness to Provide Coronavirus Disease (COVID-19) Services and the Needs to Support COVID-19 Testing, Management, and Prevention
}

\author{
Elaine Nguyen ${ }^{1} \cdot$ Christopher T. Owens $^{2} \cdot$ Tayler Daniels $^{1} \cdot$ Jeremy Boyle ${ }^{1} \cdot$ Renee F. Robinson $^{3}$ (D)
}

Accepted: 31 October 2020 / Published online: 6 November 2020

(c) Springer Science+Business Media, LLC, part of Springer Nature 2020

\begin{abstract}
The need for increased testing is pivotal in the response to the coronavirus disease (COVID-19) pandemic. Recently, through the Public Readiness and Emergency Preparedness (PREP) Act, pharmacists were given the ability to order and administer COVID-19 tests, giving them a better opportunity to engage in the pandemic response across the nation as well as in Idaho. This survey sought to determine Idaho pharmacists' willingness to provide different COVID-19 related services, assess needed resources to provide such services, and identify and prioritize other unmet community needs. We conducted a ninequestion, cross-sectional survey distributed to pharmacists with addresses located in Idaho. All questions in the survey were optional and focused on pharmacist's willingness to provide services, what resources and additional training they would need, difficulty with 90-day prescriptions, and solicited additional feedback using an open-ended question. A total of 229 responses were received, representing all areas of pharmacy practice, with approximately half from community settings. The majority of respondents (70\%) were willing to provide COVID-19 testing. Adequate staffing, changes to workflow, and the need for billing and clear reimbursement mechanisms were most frequently cited as barriers to contributing to the COVID19 response. In summary, we found that pharmacists are very willing to help during this crisis, but their involvement may be better facilitated with the removal of barriers.
\end{abstract}

Keywords COVID-19 $\cdot$ COVID-19 diagnostic testing $\cdot$ Pharmacists $\cdot$ Community pharmacy services $\cdot$ Public health

\section{Introduction}

The coronavirus disease 2019 (COVID-19) pandemic has had widespread negative ramifications, especially for the United States (US). Given the extent of community spread, the US Department of Health and Human Services (DHHS) has stressed the need to increase testing and the number of

Electronic supplementary material The online version of this article (https://doi.org/10.1007/s10900-020-00946-1) contains supplementary material, which is available to authorized users.

Renee F. Robinson

robiren2@isu.edu

1 Idaho State University College of Pharmacy, Meridian, USA

2 Idaho State University Kasiska Division of Health Sciences, Pocatello, USA

3 University of Alaska Anchorage/Idaho State University College of Pharmacy, 2533 Providence Drive, PSB 108B, Anchorage, AK 99508, USA available testing sites across the nation and is working with some pharmacies to provide community-based testing sites [1].

Pharmacists are one of the most accessible healthcare professionals and in certain (especially rural) communities, they may be the only available healthcare professional [2]. In most states, pharmacies can provide Clinical Laboratory Improvement Amendments (CLIA)-waived tests to help manage chronic diseases (e.g., glucose and cholesterol testing) and identify acute illnesses (e.g., strep throat and influenza) outside of laboratories [3]. Given their accessibility, capabilities, and clinical knowledge, pharmacy organizations came together to release joint policy recommendations to combat COVID-19 [4]. Recommendations included authorizing pharmacists to participate in testing and treatment for infectious diseases, operate across state lines and utilize health information technology, conduct therapeutic interchanges and substitution for drug shortages, and remove barriers to service provision ensuring reimbursement for services. Such authorizations would allow pharmacists to more 
fully and effectively support the nation's growing healthcare system demands during this time, as they have done with other health crises in the past.

Pharmacists have been longtime key players in immunization efforts. During the 2009 swine flu (H1N1) pandemic, there was a shift in vaccination practices from medical offices to pharmacies [5]. While pharmacists in select states have been able to administer vaccinations prior to 2009, it was during this time that pharmacists in all 50 states were able to do so for the first time [6]. Since then, vaccinations in pharmacies have increased with each passing influenza season $[5,7,8]$.

As with previous pandemics, rapidly expanding testing for COVID-19 is a crucial part of our nation's response. As such, the DHHS Office of the Assistant Secretary issued guidance through the Public Readiness and Emergency Preparedness (PREP) Act authorizing licensed pharmacists to order and administer COVID-19 diagnostic tests [9]. This increased the opportunity for pharmacists across the nation, as well as in Idaho, to assist in the pandemic response.

Idaho is a predominantly rural state with nearly all counties considered health professional shortage areas [10,11]. Given health access concerns across the state, pharmacists can be leveraged to provide COVID-19 health services and assist their communities. Thus, we sought to determine Idaho pharmacists' willingness in providing COVID-19 services and assess their perceptions of needed resources to provide such services.

\section{Methods}

We conducted a cross-sectional survey across Idaho. The electronic survey was designed to take less than five minutes and included nine questions. Questions (Online Appendix 1) asked about willingness to provide different COVID-19 services, resources needed for service provision, infographics materials that would be helpful for communities, and problems filling 90-day prescriptions for patients. Open-ended questions inquiring about any other thoughts and contact information were also included. All questions were optional.

The survey was designed from a similar assessment done in Alaska by the Alaska Pharmacists Association. Project team and Idaho Pharmacy Leadership Council (IPLC) members modified the survey to better meet the needs of the state. The IPLC is a joint body with representatives from Idaho pharmacy education (Idaho State University [ISU] College of Pharmacy), regulatory agencies (Idaho Board of Pharmacy [BOP]), and professional organizations (Idaho Society of Health-System Pharmacists, Idaho State Pharmacy Association).

The survey was distributed by ISU's Associate Vice President for Health Sciences, an active and well-known pharmacist across the state, on behalf of the IPLC on April 28,2020 via email. It was sent to all active pharmacists registered with the BOP and an Idaho mailing address $(\mathrm{N}=1683)$. No reminder emails were sent. The survey was administered through Qualtrics (Qualtrics, Provo, Utah), a secure, web-based survey application.

Four-weeks after survey distribution, all responses were exported into a spreadsheet for data analysis. We excluded responses from pharmacists not working in Idaho (when this information was available). We used descriptive statistics with data reported as counts and percentages. For the open-ended question inquiring about any other thoughts, we coded responses using an inductive approach. Project team members independently reviewed responses to this question and created a draft code list of identified themes. Then, as a group, a consensus code list was determined and themes were linked to responses. This allowed us to organize and categorize responses to better understand pharmacists' unmet needs.

This work was deemed non-research and exempt from further review by ISU's Institutional Review Board.

\section{Results}

The survey was completed by 229 pharmacists (13.6\% response rate). Note that all pharmacists with an Idaho mailing address may not be working in Idaho; therefore, response rate may be higher. Nearly three-quarters of respondents $(n=168)$ provided their contact information with work setting details. Almost half of pharmacists $(n=107)$ work in a community/retail setting (Table 1). Overall, respondents indicated a willingness to provide COVID-19 services, if available. More than $70 \%$ said they would definitely or probably be willing to provide COVID-19 antigen $(n=162)$ and antibody $(n=179)$ testing, respectively. Approximately $90 \%$ of pharmacists were definitely/probably willing to prescribe antiviral therapy $(\mathrm{n}=206)$ and administer and/or prescribe immunizations $(n=205)$. When evaluated by practice setting, similar patterns were seen (Table 2).

In order to provide COVID-19 services, pharmacists most needed education/training, followed by supplies for service provision, a reimbursement mechanism for supplies and medical services provided, and staffing and workflow modifications (Fig. 1).

When asked what infographic topics would be helpful for the community, pharmacists said the following: COVID19 testing $(\mathrm{n}=192,83.8 \%)$ and risk $(\mathrm{n}=164,71.6 \%)$, what pharmacists can do $(\mathrm{n}=159,69.4 \%)$, [vaccines and herd] immunity $(n=139,60.7 \%)$, appropriate use of healthcare services $(n=114,49.8 \%)$, emergency preparedness, $n=85$, $37.1 \%$, and other $\mathrm{n}=9,3.9 \%$ ). Other responses included 
Table 1 Practice setting of Idaho pharmacist respondents $(\mathrm{N}=229)$

\begin{tabular}{ll}
\hline Practice setting & $\mathrm{n}(\%)$ \\
\hline Community & $107(46.7)$ \\
Chain drugstore & $15(6.6)$ \\
Supermarket & $39(17.0)$ \\
Mass merchandiser & $17(7.4)$ \\
Independent & $30(13.1)$ \\
Unspecified & $6(2.6)$ \\
Non-federal health-system ${ }^{\mathrm{a}}$ & $25(10.9)$ \\
Inpatient & $2(0.9)$ \\
Ambulatory care & $3(1.3)$ \\
Outpatient pharmacy & $2(0.9)$ \\
Unspecified & $18(7.9)$ \\
Federal Health-System & $5(2.2)$ \\
Academia & $4(1.7)$ \\
Mixed & $10(4.4)$ \\
Other & $17(7.4)$ \\
Unknown & $61(26.6)$ \\
\hline
\end{tabular}

${ }^{a}$ Health-system was defined (following the Agency for Healthcare Research and Quality's definition) as a connected organization of at least one hospital and one group of physicians providing comprehensive care

elaboration of topics as well as appropriate use of personal protective equipment (PPE).

Only $6.7 \%(\mathrm{n}=15)$ of pharmacists indicated having problems getting 90 -day prescriptions approved by insurers for patients, specifying they needed help because most insurance companies limit fills to 30 -days and some insurers will only pay for 90-day supplies if patients receive prescriptions through mail-order. The majority of pharmacists had no issues with 90 -day prescription approvals $(\mathrm{n}=183,81.7 \%)$ and $11.6 \%(\mathrm{n}=26)$ selected "other" to this question, and did so because they do not work in an applicable setting.

Themes identified from responses to the open-ended text field revealed the following needs: safety precautions and PPE, provider status and reimbursement, and assistance with workload and pharmacy logistics. Pharmacists also expressed interest (or lack of) in expanded scope opportunities related to COVID-19 services. In regard to safety precautions and PPE, one respondent noted:

pharmacist[s] are on the front line... [and] are at a greater risk because the current test is for symptomatic clients only.

Many pharmacists voiced concern regarding recognition as a healthcare provider and securing a fair reimbursement for services provided. One pharmacist stated:

although I would love to offer these services for free, our biggest obstacles would be 1) to get paid fairly to cover costs of testing supplies and staff, 2) getting staff PPE supplies at a fair price or at all, and 3) getting insurance groups to recognize pharmacists as providers and get paid for those services provided.

Related to reimbursement for service provision is workload as work is often dictated by profitable tasks. COVID-19 testing would add to workload and logistics

Table 2 Pharmacists' willingness to provide services by practice setting

\begin{tabular}{|c|c|c|c|c|c|c|c|}
\hline \multirow[t]{2}{*}{ Service } & \multicolumn{6}{|l|}{ Response } & \multirow[t]{2}{*}{ Practice setting } \\
\hline & $\begin{array}{l}\text { Definitely yes } \\
\mathrm{n}(\%)\end{array}$ & $\begin{array}{l}\text { Probably yes } \\
\mathrm{n}(\%)\end{array}$ & $\begin{array}{l}\text { Might or might not } \\
\mathrm{n}(\%)\end{array}$ & $\begin{array}{l}\text { Probably not } \\
\text { n }(\%)\end{array}$ & $\begin{array}{l}\text { Definitely not } \\
\mathrm{n}(\%)\end{array}$ & $\begin{array}{l}\text { No response } \\
\mathrm{n}(\%)\end{array}$ & \\
\hline \multirow{3}{*}{$\begin{array}{l}\text { Provide COVID-19 } \\
\text { testing, if available }\end{array}$} & $41(38.3)$ & $38(35.5)$ & $10(9.3)$ & $14(13.1)$ & $4(3.7)$ & $0(0.0)$ & Community $(\mathrm{N}=107)$ \\
\hline & $11(44.0)$ & $9(36.0)$ & $2(8.0)$ & $2(8.0)$ & $1(4.0)$ & $0(0.0)$ & $\begin{array}{l}\text { Health-System } \\
\quad(\mathrm{N}=25)\end{array}$ \\
\hline & $86(37.6)$ & $76(33.2)$ & $28(12.2)$ & $24(10.5)$ & $14(6.1)$ & $1(0.4)$ & All Settings $(N=229)$ \\
\hline \multirow{3}{*}{$\begin{array}{l}\text { Provide COVID-19 } \\
\text { antibody (point- } \\
\text { of-care) testing, if } \\
\text { available }\end{array}$} & $48(44.9)$ & $39(36.4)$ & $10(9.3)$ & $7(6.5)$ & $3(2.8)$ & $0(0.0)$ & Community $(\mathrm{N}=107)$ \\
\hline & $13(52.0)$ & $9(36.0)$ & $1(4.0)$ & $2(8.0)$ & $0(0.0)$ & $0(0.0)$ & $\begin{array}{l}\text { Health-System } \\
\qquad(\mathrm{N}=25)\end{array}$ \\
\hline & $98(42.8)$ & $81(35.4)$ & $21(9.2)$ & $18(7.9)$ & $9(3.9)$ & $2(0.9)$ & All Settings $(N=229)$ \\
\hline \multirow{3}{*}{$\begin{array}{l}\text { Prescribe antivi- } \\
\text { ral therapy, if } \\
\text { treatments for } \\
\text { COVID-19 became } \\
\text { available }\end{array}$} & $76(71.0)$ & $24(22.4)$ & $3(2.8)$ & $1(0.9)$ & $1(0.9)$ & $0(0.0)$ & Community $(\mathrm{N}=107)$ \\
\hline & $18(72.0)$ & $5(20.0)$ & $1(4.0)$ & $1(4.0)$ & $0(0.0)$ & $0(0.0)$ & $\begin{array}{l}\text { Health-System } \\
\qquad(\mathrm{N}=25)\end{array}$ \\
\hline & $145(63.3)$ & $61(26.6)$ & $8(3.5)$ & $11(4.8)$ & $4(1.8)$ & $0(0.0)$ & All Settings $(N=229)$ \\
\hline \multirow{3}{*}{$\begin{array}{l}\text { Administer and/ } \\
\text { or prescribe } \\
\text { immunizations for } \\
\text { COVID-19, if they } \\
\text { became available }\end{array}$} & $91(85.0)$ & $12(11.2)$ & $2(1.9)$ & $1(0.9)$ & $1(0.9)$ & $0(0.0)$ & Community $(\mathrm{N}=107)$ \\
\hline & $19(76.0)$ & $4(16.0)$ & $2(8.0)$ & $0(0.0)$ & $0(0.0)$ & $0(0.0)$ & $\begin{array}{l}\text { Health-System } \\
\qquad(\mathrm{N}=25)\end{array}$ \\
\hline & $176(76.9)$ & $29(12.7)$ & $12(5.2)$ & $6(2.6)$ & $5(2.2)$ & $1(0.4)$ & All Settings $(\mathrm{N}=229)$ \\
\hline
\end{tabular}


Fig. 1 Pharmacists' needs to provide services by practice setting. NPI National Provider Identifier

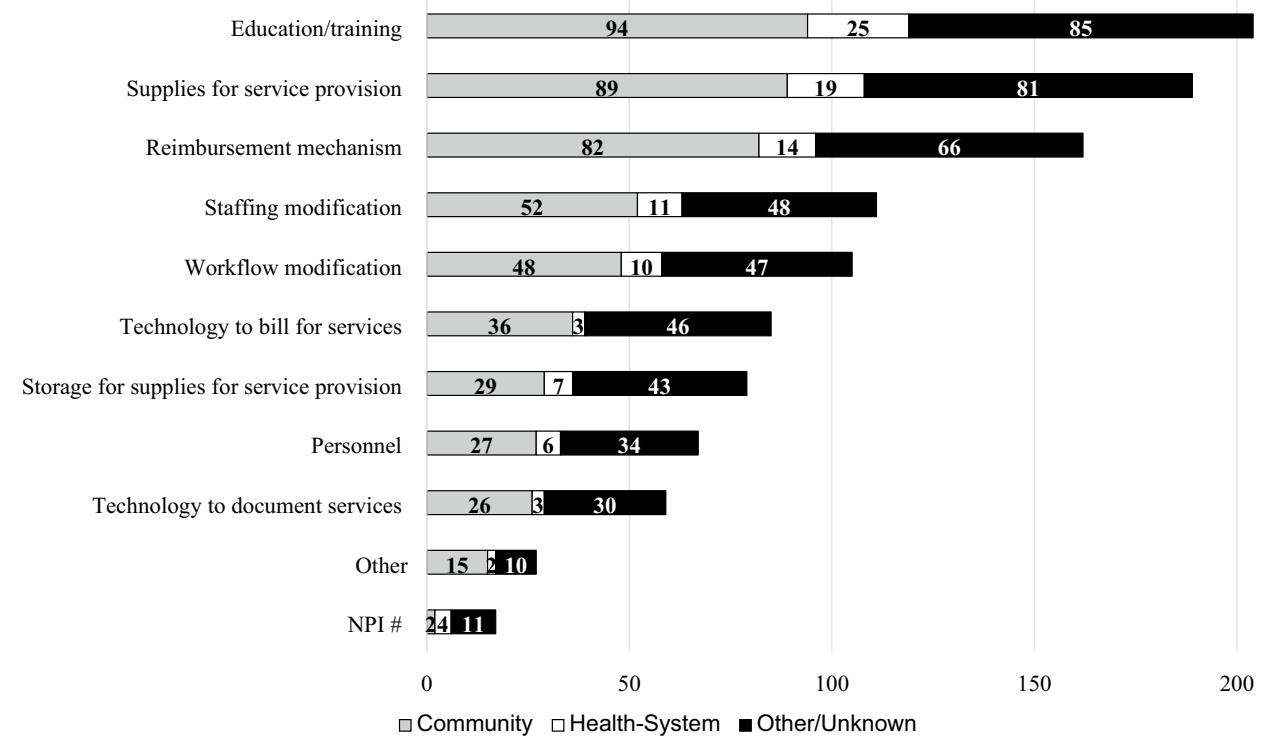

of performing testing would need to be streamlined. One pharmacist in a community setting replied:

We already work with not enough man hours to do our jobs. This would just be another metric to be measured by corporations and we would have no choice in the matter and be required to do it. We are already stretched thin, especially during flu season.

Lastly, pharmacists also made both positive and negative comments regarding pharmacists' expanded scope related to COVID-19 services. One positive response was:

I am more than willing to offer our services and expertise to the public and think it is a great opportunity to be a bigger provider of health care services.

However, other responses were more apprehensive:

...unless there are some changes to the ways things are run by corporations and regulated by the Board, I do not want to take this on this as an additional responsibility.

\section{Discussion}

Pharmacists are the most accessible healthcare professional with $94 \%$ of the population living within five miles of a community pharmacy [2]. This proximity, along with pharmacists' frequent interaction with patients (patients see pharmacists twice as often as their physicians), and the passage of the PREP Act allows pharmacists nationwide to perform COVID-19 testing and potentially meet an unmet need in their communities [12, 13]. Pharmacists are clinically capable and legally allowed to perform services beyond dispensing of medications. Idaho, along with several other states, allow pharmacists to test for and prescribe treatment for infectious illnesses such as strep throat and influenza [14]. As previously noted, pharmacists proved to be valuable members of the healthcare team in combating the $\mathrm{H} 1 \mathrm{~N} 1$ crisis by administering immunizations and educating the public. Similarly, pharmacists in Idaho are willing to assist with the current pandemic. Our results indicate that pharmacists are willing to provide COVID-19 services but need additional resources to provide these health services.

Our state-specific results align with a survey administered by the National Community Pharmacists Association (NCPA) which showed that over $50 \%$ of pharmacists are interested in performing COVID-19 testing [15]. An important finding of our survey was the interest in providing COVID-19 services by pharmacists in a variety of practice settings, from individuals practicing in smaller, independent pharmacies to those in large chain stores. Leadership in a number of national retail chain pharmacies advocate nondispensing roles for pharmacists (e.g., clinical screenings). DHHS has been able to partner with national pharmacy and grocery chains to offer COVID-19 testing [16].

Interestingly, answers from our respondents highlight potential issues for expanded pharmacists' services in these settings such as adequate staffing and the logistical feasibility of performing these roles in some busy retail settings. Independent pharmacy practitioners likewise support these roles, but in contrast, they appear to also have greater autonomy and flexibility to perform non-dispensing activities. Furthermore, independent pharmacy owners in Idaho expressed a willingness to ensure that staffing ratios are appropriate for provision of additional 
non-dispensing services. Given the lack of multilevel administration, independent pharmacies may also be more readily able to implement changes that would allow for increased COVID-19 services by pharmacists. In addition to staffing needs, the location and layout of the pharmacy was also found to be important to protect the health and safety of other patients/patrons receiving standard pharmacy services (e.g., filling prescriptions). Those pharmacies, large and small, with easier access to a drive-through or an outside parking lot would be most able to implement workflow changes to allow for mobility of necessary staff and observing the distancing and safety precautions necessary for COVID-19 antigen testing.

In addition to testing, pharmacies can support efforts to accelerate vaccination (influenza and coronavirus, when available) and other COVID-19 risk mitigation strategies such as surveillance and contact tracing. The National Association of Chain Drug Stores (NACDS), which represents the over 155,000 pharmacists filling nearly three billion prescriptions yearly in traditional drug stores, supermarkets, and mass merchants with pharmacies, notes how community pharmacy personnel currently help in identifying new cases of hepatitis $\mathrm{C}$ and human immunodeficiency virus, informing appropriate public health personnel of identification, and referring patients to appropriate next steps in care [17]. As seen with past epidemics and public health crises, pharmacy personnel are critical in providing education to the public, especially as increasing numbers of Americans delay non-emergent health care and minimize interactions with other access points to the healthcare system [18]. To better leverage pharmacies in assisting as well as taking on new roles with COVID-19, nationwide preparation efforts are needed now.

Our work has some notable limitations. Our data represents responses from only one state, but it does align with preliminary national data. We reported a $13.6 \%$ response rate, but the true denominator of pharmacists practicing in Idaho is unknown. Lastly, given the nature of cross-sectional survey analyses, we were unable to collect further elaboration of some answers. However, our open-ended question allowed respondents to freely share information and we were able to identify common themes from this question.

\section{Conclusion}

Pharmacists are accessible frontline healthcare personnel who have been able to assist in public health crises in the past and can continue to do so during the COVID-19 pandemic. We found that pharmacists are very willing to help during this crisis, but their involvement may be better facilitated with the removal of barriers.
Acknowledgements We would like to thank Idaho pharmacists for responding to this survey and members of the Idaho Pharmacy Leadership Council (Idaho State University College of Pharmacy, Idaho State Board of Pharmacy, Idaho Society of Health-System Pharmacists, Idaho State Pharmacy Association) for their support of this work.

Funding This research did not receive any specific grant from funding agencies in the public, commercial, or not-for-profit sectors.

\section{Compliance with Ethical Standards}

Conflict of interest All authors have nothing to disclose.

\section{References}

1. Office of the Assistant Secretary for Health (ASH). (2020). Community-based testing sties for COVID-19. U.S. Department of Health \& Human Services. Retrieved October 24, 2020, from https://www.hhs.gov/coronavirus/community-based-testing-sites /index.html.

2. NACDS Economics Department. (2013). What pharmacy can do to plug the gaps in health care. RX Impact Magazine. Retrieved October 26, 2020, from https://rximpact.nacds.org/pdfs/rximp act_0313.pdf.

3. National Alliance of State Pharmacy Associations. (2020). COVID-19: Testing, CLIA-waived pharmacies. Retrieved October 26, 2020, from https://naspa.us/resource/covid-19-testing/.

4. APhA, ASHP, NASPA, NACDS, HOPA, NCPA, ASCP, AACP, ACCP, CPNP, ACPE. (2020, March 3). Pharmacists as frontline responders for COVID-19 patient care. Retrieved October 26, 2020, from https://www.pharmacist.com/sites/default/files/ files/APHA\%20Meeting\%20Update/PHARMACISTS_COVID 19-Final-3-20-20.pdf.

5. Palmer K. (2019). Ten years ago, swine flu ushered in the era of drug-store flu shots. Quartz. Retrieved October 26, 2020, from https://qz.com/1722940/ten-years-ago-h1n1-swine-flu-usheredin-drug-store-flu-shots/.

6. Traynor, K. (2009). With Maine on board, pharmacists in all 50 states can vaccine: H1N1 prompts emergency vaccination for pharmacists. American Journal of Health-System Pharmacists, 66(21), 1892-1894.

7. Centers for Disease Control and Prevention. (2011). Place of influenza vaccination among adults - United States, 2010-11 influenza season. Morbidity and Mortality Weekly Report, 60(23), 781-785.

8. Zhai Y., Santibanez, T.A., O'Halloran, A., et al. (reviewed 2018). National and state-level place of flu vaccination among vaccinated adults in the United States, 2014-15 flu season. Centers for Disease Control and Prevention. Retrieved October 26, 2020, from https://www.cdc.gov/flu/fluvaxview/place-vaccinatio n-2014-15.htm\#: :text=National\%2DLevel\%20Place\%20of\%20 Flu,\%E2\%88\%9264\%20years\%20(55.8\%25).

9. Office of the Assistant Secretary for Health (ASH). (2020). Guidance for licensed pharmacists, COVID-19 testing, and immunity under the PREP Act. U.S. Department of Health \& Human Services. Retrieved October 26, 2020, from https://www.hhs.gov/ sites/default/files/authorizing-licensed-pharmacists-to-order-andadminister-covid-19-tests.pdf.

10. Bureau of Rural Health and Primary Care. (2020). Rural health and underserved areas. Idaho Department of Health and Welfare. Retrieved October 26, 2020, from https://healthandwelfare.idaho .gov/providers/rural-health-and-underserved-areas/rural-healt $\mathrm{h}$-and-underserved-areas. 
11. Bureau of Rural Health and Primary Care. (2018). Idaho primary care health professional shortage areas. Idaho Department of Health and Welfare. Retrieved October 26, 2020, from https:// publicdocuments.dhw.idaho.gov/WebLink/DocView.aspx?id=1 $807 \& \mathrm{dbid}=0 \&$ repo $=$ PUBLIC-DOCUMENTS $\& \mathrm{cr}=1$.

12. Tusyuki, R. T., Beahm, N. P., Okada, H., \& Al Hamarneh, Y. N. (2018). Pharmacists as accessible primary health care providers: Review of the evidence. Canadian Pharmacists Journal, 151(1), 4-5.

13. Berenbrok, L. A., Gabriel, N., \& Coley, K. C. (2020). Evaluation of frequency of encounters with primary care physicians vs visits to community pharmacies among Medicare beneficiaries. JAMA Network Open, 3(7), e209132.

14. National Alliance of State Pharmacy Associations. (2019). Pharmacist prescribing: "Test and treat." Retrieved October 26, 2020, from https://naspa.us/resource/pharmacist-prescribing-for-strep -and-flu-test-and-treat/.

15. Hoey, D. (2020). Pharmacists are key to break free from COVID19 paralysis. National Community Pharmacists Association. Retrieved October 26, 2020, from https://ncpa.org/newsroom/ executive-update/2020/04/17/pharmacists-are-key-break-freecovid-19-paralysis.
16. Office of the Assistant Secretary for Health (ASH). (2020). HHS extends COVID-19 testing public-private partnership. U.S. Department of Health \& Human Services. Retrieved October 26, 2020, from https://www.hhs.gov/about/news/2020/06/30/hhsextends-covid-19-testing-public-private-partnership.html.

17. National Association of Chain Drug Stores. (2020). Pharmacies: A vital partner in reopening America. Retrieved October 26, 2020, from https://www.nacds.org/pdfs/government/2020/Pharmacies -Reopening-America-COVID-19-NACDS-May2020.pdf.

18. Czeisler, M. E., Marynak, K., Clarke, K. E. N., et al. (2020). Delay or avoidance of medical care because of COVID-19 related concerns - United States. Morbidity and Mortality Weekly Report, 69(36), 1250-1257.

Publisher's Note Springer Nature remains neutral with regard to jurisdictional claims in published maps and institutional affiliations. 